\title{
AGRICULTURA FAMILIAR E DESENVOLVIMENTO SUSTENTÁVEL: UM ESTUDO DE CASO NA COOPERATIVA AGRÍCOLA MISTA DE TOMÉ-AÇU (CAMTA) /PA
}

\section{Edson Matos Gonzaga'; Ellen Cristina Vale Da Cruz²; Ivanilde Santos Correa ${ }^{3}$; Maria do Socorro dos Santos Salgado Martins ${ }^{4}$; Agnes de Souza Costa ${ }^{5 ;}$ Myrella Katlhen da Cunha de Araujo ${ }^{6}$.}

${ }^{1}$ Discente do curso de Administração da UFRA, Tomé-Açu, PA; ${ }^{2}$ Discente do curso de Administração da UFRA, Bujaru, PA; ${ }^{3}$ Discente do curso de Administração da UFRA, Tomé-Açu, PA; ${ }^{4}$ Discente do curso de Administração da UFRA, Tomé-Açu, PA; ${ }^{5}$ Engenheira de Produção, Especialista em Gestão Empresarial, UFRA, Tomé-Açu, PA; ${ }^{6}$ Discente do curso de Engenharia Agrícola da UFRA, Tomé-Açu, PA.

DOI: 10.47094/ICONNECA.2021/2

\section{RESUMO}

Frente as práticas realizadas pela agricultura familiar e o desenvolvimento sustentável, o estudo buscou ações sustentáveis e analisar a relação da Cooperativa Agrícola Mista de Tomé-Açu (CAMTA) com a agricultura familiar no município de Tomé-Açu, adotadas na busca por Desenvolvimento Sustentável. $\mathrm{O}$ trabalho foi na sede da CAMTA, em Tomé-Açu/PA. A pesquisa foi exploratória, com levantamento literário, informações do site da CAMTA e do governo paraense. Ainda, realizada uma entrevista com o Diretor Membro da Cooperativa, com aplicação de questionário (18 perguntas subjetivas). Os dados foram qualitativos. Como resultado, a CAMTA se mostrou referência nas práticas agrícolas, com muitas oportunidades de parceria para agregar valor aos produtos dos cooperados. Exemplo, é o fornecimento de produtos sustentáveis à Natura, produzidos através de boas práticas. $\mathrm{O}$ destaque é resultado da associação da agricultura familiar à sustentabilidade através do SAFTA, modelo de referência nacional em desenvolvimento socioeconômico e de preservação à floresta amazônica.

PALAVRAS-CHAVE: Sustentabilidade. Desmatamento. Cooperativa.

ÁREA TEMÁTICA: Outros.

\section{INTRODUÇÃO}

Diante da atual caracterização da agricultura familiar, os agricultores devem conhecer sua responsabilidade sobre as mudanças nos paradigmas de desenvolvimento, visto a influência direta no meio ambiente, e que suas ações devem estar pautadas em princípios sustentáveis para o desenvolvimento sustentável (SILVA; TORRES, 2018). Nesse contexto, o município de Tomé-Açu, Estado do Pará, foi colonizada a partir da chegada dos primeiros japoneses na Amazônia, em 1929. No início plantavam apenas hortaliças, entretanto, visto a detenção de terras produtivas, houve a 
intensificação na agricultura, dando destaque ao município (HOMMA, 2009).

Além de configurar sua produção na agricultura familiar, o cultivo diversificado através do sistema agroflorestal (SAF) é o principal modo de cultivo dos associados da Cooperativa Agrícola Mista de Tomé-Açu (CAMTA), consistindo em uma forma sustentável de manter o ecossistema amazônico preservado e gerar renda local. Os sistemas agroflorestais são fundamentados na utilização e manejo de recursos naturais de espécies lenhosas associadas a culturas agrícolas ou animais em uma mesma área, de forma simultânea ou temporal (MARTINS et al., 2019).

Utilizando como base do sistema de produção a agricultura familiar foi criada a Cooperativa Agrícola Mista de Tomé-Açu (CAMTA). Desde sua fundação, em 1931, como Cooperativa de Hortaliças (LOUREIRO et al., 2020) teve papel fundamental no escoamento da produção para Belém e considerada a melhor cooperativa do ramo no estado do Pará. Ainda, com relevância nacional, se tornou a maior produtora mundial de pimenta-do-reino (ALBUQUERQUE, 2017). Por isso, diante da forma como a CAMTA e seus cooperados produzem, este estudo buscou identificar as ações sustentáveis e analisar a relação da Cooperativa Agrícola Mista de Tomé-Açu (CAMTA) com a agricultura familiar no município de Tomé-Açu, adotadas na busca por Desenvolvimento Sustentável.

\section{METODOLOGIA}

O presente estudo foi realizado na sede da Cooperativa Agrícola Mista de Tomé-Açu (CAMTA), situada no distrito de Quatro-Bocas, no município de Tomé-Açu, Pará.

Para obtenção dos dados, a pesquisa foi de caráter exploratório. De acordo com o estudo de Schambeck (2016) a pesquisa exploratória permite identificar outras pesquisas a fim de contribuir com o objetivo. Ainda, Gil (2017) reitera que a coleta dos dados pode ser a partir do levantamento literário, entrevistas e por análise de exemplos.

Como método de coleta exploratória, foi realizada uma pesquisa bibliográfica que conta com o levantamento de material impresso, como: livros, revistas, jornais, teses, dissertações e anais de eventos científicos (GIL, 2017). Dessa maneira, foram utilizados como fonte principal de pesquisa os materiais publicados e informações do site oficial da CAMTA e de sites oficiais do governo do estado. Para mais, em 11 de setembro de 2019 foi realizada uma entrevista com o Diretor Membro Dinaldo Santos, na sede da Cooperativa, com a aplicação de questionário. Os questionários são uma ferramenta muito utilizada devido ao baixo custo, aceitação, aplicabilidade e rapidez ao adquirir os dados (BACIL et al., 2018).

O questionário foi configurado por dezoito perguntas subjetivas relacionadas à forma que a empresa está ligada à sustentabilidade, relacionamento com a agricultura familiar, projetos presentes e futuros, parcerias da empresa, e demais relevâncias. Os dados coletados foram verificados de forma qualitativa. A análise qualitativa permite a avaliação multidimensional dos fenômenos, capturar diferentes perspectivas de uma situação e auxiliar a compreensão do indivíduo sobre determinado 
assunto (ALVES; SILVA, 1992).

\section{RESULTADOS E DISCUSSÕES}

Segundo Tafner Junior e Silva (2011) a CAMTA é pioneira no município de Tomé-Açu, juntamente a cultura nipo-brasileira, na forma de implantar novos conceitos para desenvolver em meio à agricultura e o desenvolvimento sustentável. Desde seu surgimento, em 1931, preocupa-se com a obtenção de lucro sem causar danos ao meio ambiente.

Como resultado disso, a CAMTA (2019) demonstrou ser exemplo em desenvolvimento sustentável na região. Pois a Cooperativa tem como maior aliado o sistema agroflorestal (SAF) introduzido pela agricultura familiar local. Ainda, a cooperativa afirma que o método de cultivo foi inspirado no cotidiano de povos ribeirinhos amazônicos, que plantavam em seus quintais o policultivo de árvores frutíferas e florestais, imitando a Floresta.

O Diretor Membro da CAMTA, Sr. Dinaldo, relatou que a Cooperativa está presente na agricultura há aproximadamente 70 anos (após a nomeação como CAMTA), e se denomina como pilar de sustentação desde a época que começou a colonização japonesa em Tomé-Açu. Atualmente possui 172 cooperados, sendo 70\% agricultores descendentes de japoneses e $30 \%$ de cametaenses e tomeaçuenses. Por isso, além da geração de emprego local, a cooperativa afirma preocupar-se com as mudanças climáticas globais e conscientizar seus associados a praticarem o SAFTA (Sistema Agroflorestal de Tomé-Açu) em suas propriedades agrícolas.

Conforme o INPI (2019), a dinâmica social, cultural e econômica da cidade de Tomé-Açu gira em torno da Cooperativa e da agricultura. Desde sua fundação, há uma preocupação na manutenção de programas voltados à saúde, educação e lazer dos associados. Por isso, a Cooperativa passou a manter um hospital, escolas e postos de saúde, além de patrocinar atividades esportivas sem perder o foco em promover a agricultura e a comercialização dos produtos das famílias associadas.

Ademais, como fruto do sucesso regional, o INPI (2019) descreve que em janeiro de 2019 o cacau de Tomé-Açu adquiriu a concessão do selo de Indicação Geográfica da espécie Indicação de Procedência, caracterizando uma grande conquista de geração de valor para a cidade.

\section{CONCLUSÃO}

A CAMTA se mostrou uma grande referência nas práticas agrícolas, e através disso, há muitas oportunidades de parceria para agregar valor aos produtos dos seus cooperados. Um exemplo é a parceria com a Natura, ao fornecer produtos sustentáveis produzidos através de boas práticas. $\mathrm{O}$ destaque dado a Cooperativa é resultado da associação da agricultura familiar à sustentabilidade através do SAFTA, modelo de referência nacional em desenvolvimento socioeconômico e de preservação à 
floresta amazônica. A cooperativa atenta à Responsabilidade Social, pois proporciona boas condições de vida para seus colaboradores, cooperados e familiares, sendo evidente que a postura da Cooperativa está de acordo com as questões sociais, ambientais e econômicas locais.

\section{PRINCIPAIS REFERÊNCIAS}

ALBUQUERQUE, M. S. B. Capital social e desenvolvimento local: Uma análise a partir da atuação da Cooperativa Agrícola Mista de Tomé-Açu (CAMTA), no município de Tomé-Açu/ PA. Dissertação (Mestrado) - Universidade Federal do Pará, Núcleo de Altos Estudos Amazônicos, Programa de Pós-Graduação em Gestão Pública, Belém, p. 98, 2017.

ALVES, Z. M. M. B.; SILVA, M. H. G. F. D. Análise qualitativa de dados de entrevista: uma proposta. Paidéia (Ribeirão Preto), Ribeirão Preto, n. 2, p. 61-69, 1992.

BACIL, E. D. A.; PIOLA, T. S.; WATANABE, P. I.; SILVA, M. P.; LEGNANI, R. F. S.; CAMPOS, W. Reprodutibilidade de um questionário de atividade física em escolares de 9 a 15 anos de idade. TEMAS LIVRES. Ciênc. saúde colet., Online, v. 23, n. 11, 2018.

CAMTA - Cooperativa Agrícola Mista de Tomé-Açu. (2019). Sustentabilidade. Disponível em $:<$ https://www.camta.com.br/index.php/sustentabilidade>. Acesso em: Jan. 2021.

GIL, A. C. Como elaborar projetos de pesquisa. 6. ed. São Paulo: Atlas, 2018.

HOMMA, A. K. O. Dinâmica dos sistemas agroflorestais: o caso da colônia agrícola de Tomé-Açu, Pará. Embrapa Amazônia Oriental. p.1-12, 2004.

INPI. Revista de Propriedade Industrial. No 2508, 29 de janeiro de 2019. Disponível em: < http:// revistas.inpi.gov.br/pdf/Indicacoes_Geograficas2508.pdf>. Acesso em: Jul. de 2020.

LOUREIRO, J. P. B.; FUKUSHIMA, F. M.; SOUZA, P. C. S.; SOARES, P. S.; PESSOA, T. B. Estudo da identificação dos problemas rotineiros e cálculo do nível de eficiência nos processos industriais da Cooperativa Mista de Tomé-Açu (CAMTA). Braz. Ap. Sci. Rev, Curitiba, v. 4, n. 4, p. 2418-2429, 2020.

MARTINS, E. M.; SILVA, E. R.; CAMPEllO, E. F. C.; NOBRE, C. P.; CORREIA, M. E. F.; RESENDE, A. S. O uso de sistemas agroflorestais diversificados na restauração florestal na Mata Atlântica. Ciênc. Florest., Santa Maria, v. 29, n. 2, p. 632-648, 2019.

SCHAMBECK, R. F. Inclusão de alunos com deficiência na sala de aula: tendências de pesquisa e impactos na formação do professor de música. Revista da ABEM, Londrina, v.24, n.36, p. 23-35, 2016.

SILVA, R. A.; TORRES, M. B. R. Práticas Sustentáveis e Agricultura Familiar: estudo de caso de 
agricultores cooperados da Coopapi, Apodi - RN. Revista IDeAS, Rio de Janeiro, v.12, p. 1-22, 2018. TAFNER JUNIOR, A. W.; SILVA, F. C. A História Emblemática da Cooperativa Agrícola Mista d Tomé-Açu no Nordeste Paraense. In: IX Congresso Brasileiro de História Econômica $10^{\text {a }}$ Conferência Internacional de História de Empresa, Anais... 2011, Curitiba. 